\title{
ARTICLE
}

\section{Working with offenders: challenges to the recovery agenda ${ }^{\dagger}$}

\author{
Eluned Dorkins \& Gwen Adshead
}

\begin{abstract}
Eluned Dorkins is a consultant forensic psychiatrist at Langdon Hospital in Dawlish, UK. Gwen Adshead is a consultant forensic psychotherapist at Broadmoor Hospital in Crowthorne, UK. Correspondence Eluned Dorkins, Consultant Forensic Psychiatrist, Langdon Hospital, Exeter Road, Dawlish EX7 ONR, UK. Email: eluned.dorkins@nhs.net
\end{abstract}

${ }^{\dagger}$ For a commentary on this article see pp. 188-190, this issue.

\begin{abstract}
SUMMARY
Recovery approaches are now being developed in forensic as well as general mental health services. These are welcome developments that offer new ways of working with a socially excluded group of patients. However, the theoretical basis of recovery, with its individual humanistic ethos, may struggle to articulate the unique problems of forensic service users. In this article, we describe those problems and propose a 'third way' of thinking that bridges the recovery agenda (which looks for the best in people) and the forensic agenda (which must consider the worst in people). We propose using a 'narrative approach', which sees the forensic service user's offence and cruelty as part of their human story. We link this explicitly with the work of Dan McAdams and his concept of the redemption narrative.
\end{abstract}

\section{DECLARATION OF INTEREST}

None.

The College's 'Fair Deal' campaign calls for 'a coherent policy based on recovery-orientated practice' (Royal College of Psychiatrists 2008). There are already many well-established recoverybased initiatives working within a range of services in the UK (Royal College of Psychiatrists 2007). The recovery approach also has great potential value for forensic services, as we describe below. However, we suggest that forensic service users have unique difficulties that present a challenge to current recovery models. In particular, we ask whether and how recovery models can address service users' antisocial values and beliefs and we give clinical examples of particularly complex cases that we have seen. We do not seek to criticise recovery approaches as a whole or undermine helpful service initiatives. Rather, we raise questions and offer a solution based on the theory of personal identity as a life narrative.

\section{What is recovery?}

The concept of 'recovery' in mental health services encompasses a variety of approaches that seek to alter the balance of power and priorities between professionals and service users. A widely accepted definition of personal recovery is that of William Anthony (1993):

'Recovery is a deeply personal unique process of changing one's attitudes, values, feelings, goals, skills, and /or roles. It is a way of living a satisfying, hopeful, and contributing life even within the limitations caused by illness. Recovery involves the development of new meaning and purpose in one's life as one grows beyond the catastrophic effects of mental illness.'

Of central importance is the distinction between 'clinical' and 'personal' recovery (Slade 2009). The first, in its crudest form, is the traditional bioscientific concept of recovery, which is an observable outcome or state, rated by expert clinicians and invariant across individuals (p.35). By contrast, personal recovery is seen as 'a journey into life, not an outcome to be arrived at' (p.38) and may overlap with, but not be synonymous with, clinical recovery. By definition, personal recovery is a more variable and evolving activity, which is therefore hard, although not impossible, to operationalise.

It has been argued that personal, not clinical recovery alone, should be the remit of mental health services because personal recovery emphasises individual values and relationships and the predominance of human identity over patient role. It follows that there is not one single recovery model for mental health services; rather, there is a plurality of recovery-focused services, which offer 'a set of attitudes and values put into practice by skilled mental health practitioners' (Slade 2009: p. 38).

\section{Recovery in forensic psychiatry}

Recovery models could potentially be of real value to forensic service users. These patients are typically highly socially disadvantaged and have histories of extreme childhood adversity. They often have little experience of autonomous living, having been in some sort of 'care' all their lives. They have worse health than other mental health service users and higher rates of suicide. Worse still, they are often excluded not only from their social communities, but also from families and so face prolonged social isolation. 


\section{Recovery-based support tools}

Forensic services already use recovery-based support tools. One example is the Wellness Recovery Action Plan (WRAP; Copeland 1999), which focuses on 'what keeps me well', emphasising items such as support systems, ways of coping and self-management, as well as more illness-oriented items such as triggers. Another is the Developing Recovery Enhancing Environments Measure (DREEM; Ridgeway 2004), a self-report questionnaire developed in the USA from service user accounts of their own recovery process.

A unique feature of recovery in forensic terms is that it must include not only feeling better but also 'behaving better': a moral as well as a clinical agenda (Adshead 2000). For example, psychologists working with sex offenders use elements of positive psychology in tools such as the 'good lives' model of rehabilitation from offending (Ward 2006, 2007). This model takes a focus beyond offending, emphasising the personal qualities needed for a good and satisfying life and especially the vision that desisting from offending is possible.

\section{Recovery models in practice}

Forensic practitioners have raised questions about the implementation of recovery models in forensic services. Some comment that the social exclusion of many forensic patients is socially mandated and that in risk-averse societies socially excluded people have a lack of opportunity (Mezey 2009). They suggest that there is an 'inherent contradiction' between supporting patient choice and simultaneously pursuing their involuntary detention because of previous antisocial choices. There are also those who question whether 'recovery' has any meaning at all in forensic settings (Frese 2001; Davidson 2006).

There would seem to be four areas in which the recovery model is uniquely challenged by the needs of forensic service users. These are:

- the values and identity of forensic service users

- social exclusion as a community response to trauma and violence

- empowerment for those who misuse power and do not respect the choices of others

- hopelessness and the offender identity.

There is an obvious link here with the four domains of recovery as described by Slade (2009):

- Hope - What will happen to me?

- Identity - Who am I?

- Meaning - What has happened and what does this mean for me?

- Personal responsibility - What can I do?

\section{The values of forensic service users}

Forensic service users are a heterogeneous group because they are defined by other people's reactions to them. They rarely have a single diagnosis, especially those who are referred to residential secure care (Blackburn 2003). People are referred to forensic services because they have frightened other people or because they are too much for other carers to manage. They may be frightening in terms of their interpersonal interactions with others or in terms of their past violence, or both. They may be too much for other healthcare services to handle (in either in-patient units or prisons) because they attack carers, fellow patients or themselves. The majority of forensic service users have explicitly antisocial lifestyles and behaviours: in humanistic terms, they 'do not play well with others' and this may be all that they have in common.

Policy papers on recovery place considerable emphasis on the importance of shared values between service user and service provider. There is reference to 'shared meanings' as 'mediators of the recovery process' (Shepherd 2008: p. i). Also, where it is noted that there may be a clash of values between service users and mental healthcare professionals (Slade 2009: p. 139), it is implied that professionals ought to respect the values of the service user. We have not seen an explicit discussion of how to proceed or work with service users who are antisocial and who seek to undermine the good lives of others, such as the (fictitious) Henry in Box 1.

Some recovery models assume that all service users wish to be citizens (Slade 2009). These are challenged by service users who apparently 'choose' a value set that not only is different from that of professionals, but is profoundly antisocial and has resulted in attacks on the social value system held by the communities from which they come. The criminal justice process that has placed many service users in forensic mental health systems is

\section{B0X 1 Undermining the lives of others}

Henry charms nursing staff and invites them to break professional rules. He seeks to exploit their good nature and complains when they keep the boundaries. In his world view, prosocial people (like staff or other patients) are there to be exploited. In recovery terms, is he recovering from these values or is he 'building a meaningful and satisfying life as defined by [himself]', whether or not there are any ongoing symptoms or problems? Henry has a history of sexual boundary violations with staff and one of his 'partners' was later a victim of his violence. 
making a statement about a social condemnation of antisocial intentions and values - a condemnation that healthcare professionals are obliged to sign up to as citizens and which they may appropriately share at a personal level.

There is still great debate about whether cruel and unusual attitudes can be understood as illness or disability. Space does not permit full discussion of whether new dimensional accounts of pathology that may appear in future diagnostic systems will include vices and nasty beliefs (Sadler 2008). This issue goes beyond a simple dichotomy of 'mad or bad', where madness gets therapeutic help and badness does not. Forensic services have always offered psychological help to offenders to address their offending behaviours and states of mind, but this must mean at some level that forensic professionals are invited to try to change the patient's values, not respect them.

Given the complexity of debate, it is not surprising that professionals are likely to have different views, especially about issues that cause anxiety, such as risk of harm to others. It is not uncommon for the forensic service user to have one view of their risk and for the professionals to have another. However, typically, the forensic service user's view is supported by at least one person, who is then at odds with other professionals. Splits within and between teams with regard to patient risk (such as in the example in Box 2) are common in forensic practice (Campling 2004) and it is not always clear whether the professional is the true supporter of the patient, the dupe or the social oppressor.

Finally, there is the issue of autonomy and risk. Forensic patients are not usually allowed to define and act on their own risk. Their accounts of the risk that they pose are not usually taken at face value and clinicians may be seen as naive or reckless if they privilege the patient's view of risk. When patients' views are respected and privileged,

BOX 2 Splitting between teams

A man is held in a secure treatment unit because he sends offensive and frightening mail to others. His team thinks he is doing well and sees his behaviour as a symptom of his distress arising from his experience as a victim of childhood abuse - a view with which he agrees and that allows him to feel understood. However, an external team providing a second opinion notes that he is still sending the offensive material from the unit and that his care team is not discussing this with him in treatment. The treating team was upset that the external team's view was that the man was still dangerous; the external team felt that its views were not heard or understood.
B0X 3 An unwelcome return

A patient can't go home because his 'community' doesn't want him. Specifically, the family of his victim (whom he killed 20 years ago) is upset by any suggestion that he be transferred to a rehabilitation unit near his family and social contacts. Why do his victim's family's views matter more than his? If he had gone to prison, would this issue have applied then?

and if disasters happen subsequently, clinicians who were attempting to respect the patient's autonomy have been criticised (Scotland 1998; NHS London 2006).

\section{Social exclusion: a community of the excluded}

Forensic service users are socially excluded for a range of reasons (Mezey 2009). An underlying imperative of recovery includes 'being able to take on meaningful and satisfying social roles within local communities' (Shepherd 2008: p. i), which assumes that (a) society wants to include you and that (b) if you think 'right', you will be included. Many communities do not want to have their offenders back (Box 3).

Most of the recovery literature seems to have addressed itself to recovery from mental illnesses such as schizophrenia together with other chronic psychotic disorders, even though it has claimed to be transdiagnostic in its scope (Slade 2009). It may be that there is still more work to be done on how best to apply recovery models to personality disorder, which is better viewed as a disability rather than an illness (Adshead 2009). Even where there are forensic service users who have offended solely as a causal result of psychotic disorders, these people are a minority (and are often still excluded from their communities of origin because of the enormity or strangeness of their offence). More commonly, the service user's psychosis responds well to treatment, but this 'recovery' reveals an antisocial world view. Slade's recovery model emphasises the personal responsibility of the service user for their illness and its management, but there is work to be done on how this will be rolled out for patients who do not wish to or are struggling to take responsibility not only for the symptoms of their disorders, but also for the social outcomes.

Forensic patients are socially excluded, so there may be a particular challenge for maintaining hope. This may be an issue for both patients and staff in forensic services, especially when the offences involve homicide and sexual offences, 
which fundamentally change a person's identity. There is a balance to be struck between appropriate hope for what is possible and the validation of grief for what is not. It is demanding for professionals to tolerate and validate feelings of hopelessness, grief and regret.

\section{Empowerment and professional boundaries}

Professional boundaries help to construct professional identity, which may be crucially different from the identity of being a patient. This protects both the service user and the professional and makes the therapeutic space safe for a person who is vulnerable while recovering. However, most recovery models promote a flattening of the hierarchy between service users and professionals so that the patient is the 'expert' and their view of their illness, management and prognosis is as good or even better than that of the professionals. In general mental health services, such an approach is rich and constructive. However, it is problematic in forensic work, where there are social demands for the professionals' view to be the dominant discourse because the forensic service user's view is unreliable, antisocial and therefore risky (Box 4).

Some people might see Henry's stance as positive and forward-looking; it is also possible to see it as a narcissistic fear of appearing needy and an accompanying denigration of attempts by staff to help. It is unlikely that the Ministry of Justice or a medium secure service will discharge Henry unless and until he can provide an account of what he did that includes some remorse or regret. However, Henry does not want to do this and there is a real risk that he will be unhappy if made to. The situation is even more complicated

BOX 4 Problems with the service user's point of view

Three years ago, Henry killed his girlfriend and her children by a previous partner. The murder was brutal and included sexual violation of the bodies after death. Henry was not overtly mentally ill at the time, but as is not uncommon, the bizarreness of the offences and the public notoriety resulted in him coming to forensic services. Henry does not accept that he has any problems. He acknowledges that he did a bad thing, but feels that he has 'put it all behind him'. On the ward, he acts like a member of staff and refuses to engage in any therapies to explore the offence. Even allowing for the less-thanconscious shame and distress that Henry feels, there is a real clash of agendas and values. Henry does not want to be a patient. He regularly asserts that his view of his needs is as good as any of the professionals. when patients like Henry are very young (in which case their identity is still forming and they need authority figures in order to grow psychologically (Sutton 1997)) or when, like Henry, they are in their 60s and see no need for change.

Another example of the weakening of professional boundaries can be when professionals are encouraged to "identify examples from [their] own "lived experience" ... which inspires and validates [the service user's] hopes' (Shepherd 2008: p. 9). There is no doubt that the subjective experience of being ill and recovering may be highly effective in understanding and empathising with the experience of being a patient. Judicious self-disclosure is a potentially rich part of doctorpatient relationships. However, even such minor breaches of professional boundaries may have repercussions in work with forensic patients. They have often come from backgrounds where boundary violations were a way of life; they may also interpret sharing of personal material as a weakness to be exploited. It is often hard for generally prosocial people such as mental healthcare professionals to believe or accept that there are people who do not see the world through equally prosocial eyes. Many forensic service users are known to services because they exploit others' prosocial attitudes. Serious professional boundary violations usually begin with quite minor breaches of boundaries, usually in the realm of self-disclosure (Gabbard 1994).

It may be more honest and more helpful to say: 'I do not know what it is like to be you or to have done what you have, but I will try to listen and understand. I do not know if things can change for you, but I hope they can.' Note here that the hope is held by the professional and not the patient.

Finally, the dependence inequality between professional and patient may be an essential part of the recovery process. Relying on others and being contained promotes autonomy as much as being treated as an equal. There needs to be a flexibility of engagement, which respects the service user's need to be dependent, and sharing of control with the expert. This is a different account of autonomy - one that sees choices and decisionmaking as located in a network of relationships with others, not purely as an individual experience. This is in contrast with wider health service policy (Agich 1993; Department of Health 2007).

\section{Hope and hopelessness}

The recovery agenda emphasises hope over pessimism and the recovery of agency. In forensic settings, patients often battle with hopelessness 
and despair, which may partly explain the elevated suicide rates in this service user group. It requires extra professional skills to address despair and hopelessness - skills not unlike those found in palliative care services, where there is an emphasis on the quality of the life lived now.

However, it is essential that staff take misery and hopelessness seriously. Staff must not simply try to ignore or cheer away such important feelings, because this may cause service users to feel that they are not heard or understood. Staff need to appreciate that for these patients, the recovery challenge is to deal with and manage these feelings as they arise. Sometimes it may be important for the professional to keep the patient company while they grieve for real losses and events that cannot be changed. This is especially true in working with those who have killed, where the patient needs to get to grips with the fact that the world has changed because of their actions and that this is a disaster that has to be 'got on with' not 'got over'.

Equally, patients are sometimes unrealistically hopeful, as the example in Box 5 shows. Good clinicians have to balance hope and pessimism about the patient's narrative, treating them as real perspectives that need to be taken seriously.

\section{Taking recovery seriously: identity and meaning for forensic service users}

Most accounts of recovery emphasise the construction of personal identity and attention to the individual meaning of the experience of illness. Recovery approaches emphasise that 'Language used and the stories and meanings ... have great significance as mediators of the recovery process' (Shepherd 2008). This aspect of recovery is potentially very helpful for forensic psychiatry. Arguably, the patients in forensic services have identities that are constructed by both their illness and their offences. The identity before the offence is rarely explored.

Here, we discuss the creation of the offender identity and how the narrative of the forensic patient's experience maintains this identity. It is sometimes almost impossible for forensic patients to recover their pre-offence identities. Rather, they need help to discover a new identity that incorporates the lost self and acknowledges both the disaster that has transformed their lives and its impact on the lives of others. They are also required to accept and engage with their own potential for risk.

\section{Narratives, stories, experience}

Narratives of experience construct identity, especially at times of transition in life (Josselson 1999;
B0X 5 Service users' unrealistic hopes

A patient who killed her father said: 'Of course my mother will want me home: she's my mother'. Her plan to leave hospital as soon as possible and return to the family home was at one level perfectly understandable and made by a capacitous individual. The team was torn between supporting her agenda and the private knowledge that the family wanted nothing more to do with the patient for the time being. Staff felt unsure what to say to the patient about her family's feelings. They felt uneasy in not telling her the truth but also were very concerned that she would be upset if they did. Some staff talked about respecting the family's confidentiality, others about the duty of care to the patient and the value of honesty. It was important, in reflective practice, for the staff to be able to say that they felt guilty and afraid of being upset themselves.

Leibrich 1999; McAdams 2006). Narratives are more formal and structured versions of stories, which have been part of human culture since prehistory (Booker 2004).

Eagleton (1983) cites Gérard Genette (1980) for a description of how narratives are constructed: highlighting the order of events in the text or account; the sequence in which events actually occurred, as inferred from text; and narration, or the 'voice' that actually speaks. Eagleton notes Genette's distinctions between the 'plot' and the 'history' of events (which may not be identical), and between the process of telling the story and what is actually told. The common feature of narratives is that an original settlement is disrupted or something precious is lost, but by the end order is restored (Eagleton 1983). Anxieties about loss are stirred up but resolved in the happy ending.

Booker (2004) takes up the theme of common features of human stories. He notes the importance of transformation: a good situation becomes transformed into something disastrous or worrying and the hero/heroine acts to restore order. In that process, the central actor is also transformed, usually by means of a quest, a journey or a struggle with a monster. The 'monster' may be within the hero. Booker hypothesises that the monster to be overcome is a type of egotism that threatens social cohesion and community. In all events, there may be restoration of order, but there is a difference and a change in view for the main protagonists who are changed by their experience.

\section{Narratives of illness}

Narrative approaches to illness experience give different voices to the experience of all concerned (Kleinman 1989). Narrative experience of illness 
was initially the province of medical sociology and has developed in general medicine. It informs therapeutic initiatives such as the DiPex project in Oxford, UK (www.healthtalkonline.org).

In her influential work The Meaning of Illness, S. Kay Toombs (1993) was one of the first to argue that the patient's subjective experience of their illness was as important as professional accounts based on disease models. This was a move from a purely biological discourse ('You have severe rheumatoid arthritis') to subjective experience ('I need help to use my hands'). Professionals' accounts could be distant and detached and might reflect their own discomfort at witnessing suffering. This is especially true if they felt helpless to effect change and thus be 'heroes' in a medical 'story'.

The doctor as 'hero' is a narrative that remains socially popular in the West (as, for example, in television medical drama series) and it has been extended to other healthcare professionals. In these narratives, the doctors and nurses struggle against the monsters of disease and injury, and overcome them. There are also triumphant patient narratives about the overcoming of adversity and disability. More recently, there have been popular narratives with the doctor as monster, where the expert patient overcomes the 'horrible' healthcare professionals to gain a triumphant control over their experience.

The value of a narrative approach to understanding the experience of mental illness is demonstrated by the burgeoning literature on narratives in psychiatry and psychotherapy (Roberts 1998, 2000; Greenberg 2002). Here, the patient overcomes the monster within (e.g. Darkness Visible, Styron 1992; The Noonday Demon, Solomon 2002) or transforms their identity into one in which the 'mad' self is reconciled with the healthy self (Jamison 1996). Other accounts have described 'surviving' psychiatric care (Church 1996) - the implication being that psychiatric treatment was an ordeal.

In New Zealand, the role of the narrative as a mediator of recovery has been recognised in anthologies of recovery stories (e.g. Leibrich 1999). In the UK, some mental health trusts have also published collections of service user narratives in the same spirit (e.g. Davidson 2009). It is recognised that not all psychiatric patient narratives will make comfortable reading - some patients may have been inhumanely treated - but there may be other complex reasons for readers' discomfort.

One reason may be the nature of truth in mental health. By definition, mental disorders can compromise autonomy and may render personal narratives incoherent and unreliable, even if only temporarily. The patient with delusions is having a real experience, which is 'true' for him, but it cannot be relied on insofar as it leaves out aspects of 'truth'. The patient's account is only one perspective and may change with time, treatment or both. This is healthy and an inevitable part of psychotherapeutic work (Spence 1982).

In other settings, there may be conflict (which may not be reconcilable) between the different narratives, causing tension between the service user and the team or between different team members. One person (usually the patient) will have to give up their narrative of events and see it as not being 'true' but as being an aspect of the illness.

\section{Narratives in forensic psychiatry}

We have emphasised the issue of truth and unreliability of personal narrative because of its importance in the construction of offender identities and patienthood in forensic services. At the time of the offence, the accused's account is compared with that of the victim and other third-party witnesses and the discrepancies are noted. It is usual for the offender's narrative account to be 'trumped' by other people's stories, which are assumed to be the ‘truth' of what happened.

If the offender becomes a patient, his (or her) story is still not seen as being definitive. Indeed, he may be advised that his narrative is unacceptable or incomplete and that it needs to be revised before progress can be made. For example, in working with sex offenders, there are views of victims that appear in the patient's narrative that are explicitly challenged - a man who sees his victim as being sexually provocative will not be deemed to have 'recovered'. However, if he changes his story to fit with the prevailing medico-legal and moral discourse of the criminal court, he will be seen as being transformed and can then think about rejoining the community that excluded him.

\section{Tall tales and horror stories}

Narratives about crime are popular and powerful in Western social cultures. They may take the form of detective stories, where the detective hero overcomes the monster to restore order. Series of detective novels allow for the transformation of the hero across time (e.g. Colin Dexter's Inspector Morse and P. D. James's Inspector Dalgliesh). Films and television dramas also rely heavily on crime-as-entertainment, usually with an underlying moral message that antisocial people end up destroying themselves and will always be beaten by the heroic powers of good. Some novels 
BOX 6 Fictional narratives of offenders from differing viewpoints

Barker $\mathrm{P}$ (2002) Bordercrossing. Penguin

A child psychologist meets a young man whom he first saw years earlier when he killed an old woman. The novel explores the border between good and evil, innocence and guilt and evokes themes in the debate relevant to the case of James Bulger, the 2-year-old murdered by a two 10 -year-old boys.

Faulks S (2008) Engleby. Vintage

A first-person narrative of a murder by a university student and his account of the disappearance of a fellow student whom he has admired from afar.

Schriver L (2003) We Need to Talk About Kevin. Counterpoint Press

A mother's correspondence to her estranged husband about their son who goes on a high-school killing spree and her attempt to come to terms with it.

Sebold A (2002) The Lovely Bones. Little, Brown

The voice of a teenage murder victim who tells her story from heaven while she comes to terms with her own death and watches the lives of those she loves continue without her.

about offending now tell the story of a crime from a variety of differing viewpoints (Box 6).

Professional accounts of offending from criminology and sociology have also addressed the issue of narrative and the experience of deviance. Some have studied personal accounts of offender identity using tape-recorded interviews that offered no other view but the offender's (Parker 1994; Soothill 1999).

Forensic psychiatry and psychotherapy support transformational stories through the use of medication, psychological and occupational therapies, and support from staff and family. It is assumed that there will be a change in identity, from antisocial to prosocial, and that this process may be long and difficult. It is not only the professionals who think about this: as one of our patients said, 'You can be an ex-bus driver, but you can't be an ex-murderer'. This is a good example of the real meaning of stigma as a 'spoiled identity' (Goffman 1986). Many forensic patients have had their identities spoiled by both their offences and their mental disorders and it is unlikely that they will be able to 'recover' those past identities. In their stories, something is lost that cannot be recovered.

These themes of recovery and reconciliation emerge in clinical work with forensic patients - 'at the deep end', as has been previously explored in this journal (Roberts 2008). They have resonance with other accounts of truth and reconciliation work between offenders and victims (as in South Africa and Northern Ireland). These accounts have found that reconciliation is a process and that living with unreconciled narratives is part of that process and a painful reality.

\section{Narrative approaches to treatment in forensic settings: squaring the circle}

If we understand forensic narratives as evidence of 'damaged identities' (Lindemann Nelson 2001), then treatment approaches might understand recovery in forensic practice as the challenge of living with this damaged identity. The role of the service may be to help offender patients transform their identity, and this can be painful when some aspects of the offender identity may be changed but others may not.

There is an interesting resonance here with work by McAdams (2006) on redemption narratives in ordinary life. 'Redemption' is a concept associated with faith-based narratives and may carry overtones of judgement and condemnation, but it also includes a notion of being brought back into the social group (which looks remarkably like social inclusion). Maruna (2001) drew on a similar theme by studying redemption narratives in persistent offenders who had then given up offending. They describe a new identity, which reflects the 'new' or 'real' me, and emphasise how important it is to have social support in the transformation from an offending to a non-offending self.

Our view is that all forensic patients need psychological therapies to help them with their narrative of recovery and transformation. Group approaches are particularly valuable so that offender patients will hear other voices apart from their own. Each patient's story will be one of a plurality of narratives that can include victim, families, communities, staff and therapists. In therapeutic groups, patients can explore their personal story, which is always there to be recounted and reviewed from different perspectives. Hearing other people's stories in groups helps to reduce a sense of fear, shame and isolation, and may make it safer to remember and be reconciled to an offender identity.

Groups in different parts of the services may reflect different aspects of the patient's experience. For example, on the ward a patient may be helpful and charming, but in therapy sessions he is condescending and belittling. Putting these different experiences of the patient together in group reflective practice for staff helps to produce an integrated narrative and a more complete story. 
All therapeutic endeavours involve listening to the patient's story. It is our experience that patients come into forensic settings with a 'cover story' for their offence and for their admission. It may take some time for this story to be modified and for a fuller truth to emerge. There is a professional art to allowing patients to tell their own story their way and still raise the questions 'Is there another way to think about this? Might others see it differently?'

It may also be important to understand that the 'cover story' is face-saving and protects against shame and hopelessness. The patient fears that they will be overwhelmed by those feelings and may hold on to their story aggressively. It can be helpful to let the patient know that the professional understands how difficult it must be to have their story challenged. It may also be important to understand that antisocial identity and values may have been developed during a childhood that was frightening and traumatic, and therefore might have been life-saving at one time (Vaillant 1995).

If recovery is a 'journey of the heart' (Deegan 1996), then for offenders the heart in question may have to be reconnected to the social world from which they have been isolated. This reconfigures social inclusion as re-attachment to social structures and relationships. Narratives of reconnection may at one level conflict with an individualist approach to choice. However, in other ways they may see recovery as being about reconnection to caring and being cared for, and not choices in isolation. Hence, for many offender patients, being independent and 'left alone' to manage themselves is not helpful in promoting prosocial and community identities.

\section{Where next for forensic recovery?}

The development of recovery-based services emphasises the personal qualities of staff as much as their qualifications. The competencies required include the capacity for hope, creativity, care, compassion, realism and resilience (Gilbert 2009). Although the new curricula for psychiatric training helpfully acknowledge the importance of appropriate attitudes and skills, it remains to be seen whether staff can be trained to acquire these capacities.

If forensic professionals are going to be able to help forensic service users develop new narratives of identity, they will have to learn how to use their personal qualities in a professional manner. They also need to be aware of and manage strong personal feelings towards their patients. This is a particular challenge in residential forensic services, where it is easy to exploit professional relationships for personal gain. This is at the root of most professional boundary violations, where the personal gain in question may only be that the professional feels happy, comforted or free from anxiety.

Many ethical conflicts in mental healthcare relate to staff feeling uncomfortable. In the case described in Box 5, staff felt unsure what to say to the patient whose family did not want her home. Staff members working in forensic settings need to be able to listen to horrible narratives and 'cover stories' without being quick to either accept or challenge. They have to manage conflict with patients without either appeasing them in a compliant way or confronting them in a dominant and authoritarian way. Empathy with patients in forensic settings may mean that professionals get in touch with unpleasant feelings, which is why acting out by staff is common in residential institutions.

We suggest that the personal qualities of all staff (including doctors, nurses and other therapists) should reflect a stance or frame of mind that can tolerate uncertainty and can contain and reflect feelings. Staff need a prosocial view so that they work with each other and do not undermine different treatment techniques. Teams need a shared narrative of what the purpose of treatment is and an understanding that different team members all contribute.

Finally, recovery in the forensic context raises questions about outcomes in forensic psychiatry. Lord Bradley (Department of Health 2009) has called for a review of outcomes in forensic in-patient services. Will this include more than reoffending rates and adherence to medication? And if it does not, how does this square with the policy requirements to think about recovery (Sainsbury Centre for Mental Health 2010)?

\section{Conclusions}

The recovery agenda privileges the service user's narrative, as defined by the person himself. This discourse has its origins in the post-war challenge to normative dominance, such as civil rights for all citizens, feminism, disability rights and 'queer studies'. Fundamentally, such discourses assume that all accounts of experience are positioned in a narrative landscape and personal accounts need to be respected and are equally valid.

However, criminal offending is defined as a breach of social norms. For forensic patients, recovery will mean not only restoration of mental health, but reconnection to the social values of the group that excluded them. Each patient's narrative needs to be seen in the wider context of the many voices that make up the diverse society to which
MCQ answers

$\begin{array}{lllll}1 \mathrm{a} & 2 \mathrm{c} & 3 \mathrm{a} & 4 \mathrm{e} & 5 \mathrm{~b}\end{array}$ 
they hope to return. Forensic professionals need to be able to balance appropriate hope and pessimism and tolerate negative affects, including being seen by the patient as 'the enemy'. Recovery may mean a profound change of identity for the patient.

\section{Acknowledgement}

Thanks to Dr Glenn Roberts for his thoughtful feedback on an earlier draft.

\section{References}

Adshead G (2000) Care or custody? Ethical dilemmas in forensic psychiatry. Journal of Medical Ethics 26: 302-4.

Adshead G (2009) Systemic thinking and values-based practice. Advances in Psychiatric Treatment 15: 470-8.

Agich G (1993) Actual autonomy and long-term care decision making. In Long-Term Care Decisions. Ethical and Conceptual Dimensions (eds LB McCullough, NL Wilson): 113-36. Johns Hopkins University Press.

Anthony WA (1993) Recovery from mental illness. The guiding vision of the mental health service system in the 1990s. Psychosocial Rehabilitation Journal 16: 11-23.

Blackburn R, Logan C, Donnelly J, et al (2003) Personality disorders, psychopathy and other mental disorders. Comorbidity among patients at English and Scottish high secure hospitals. Journal of Forensic Psychiatry and Psychology 14: 111-37.

Booker C (2004) The Seven Basic Plots. Why We Tell Stories. Continuum International Publishing.

Campling P. Davies S, Farquharson G (eds) (2004) From Toxic Institutions to Therapeutic Environments: Residential Settings in Mental Health Services. Gaskell.

Church K (1996) Forbidden Narratives: Critical Autobiography as a Social Science. Routledge.

Copeland M (1999) Wellness Recovery Action Plan. Peach Press.

Davidson L, O'Connell M, Tondora J, et al (2006) The top ten concerns about recovery encountered in mental health system transformation. Psychiatric Services 57: 640-5.

Davidson L, Lynn (eds) (2009) Beyond the Storms: Reflections on Personal Recovery in Devon. Devon Partnership NHS Trust and Recovery Devon.

Deegan P (1996) Recovery as a journey of the heart. Psychiatric Rehabilitation Journal 19: 91-7.

Department of Health (2007) Choice Matters 2007-8: Putting Patients in Control. Department of Health.

Department of Health (2009) The Bradley Report. Department of Health. Eagleton T (1983) Literary Theory: An Introduction. Basil Blackwell.

Frese FJ, Stanley JD, Kress K, et al (2001) Integrating evidence-based practices and the recovery model. Psychiatric Services 52: 1462-8.

Gabbard GO, Wilkinson SM (1994) Management of Countertransference with Borderline Patients. American Psychiatric Press.

Genette G (1980) Narrative Discourse. Basil Blackwell.

Gilbert P (2009) Introducing compassion-focused therapy. Advances in Psychiatric Treatment 15: 199-208.

Goffman E (1986) Stigma: Notes on the Management of Spoiled Identity Originally. Touchstone.

Greenberg M, Shergill SS, Szmukler G, et al (2002) Narratives in Psychiatry. Jessica Kingsley.

Jamison KR (1996) An Unquiet Mind. Random House.

Josselson R, Lieblich A (1999) Making Meaning of Narratives. Sage Publications

Kleinman A (1989) The Illness Narratives: Suffering, Healing and the Human Condition. Basic Books.
Leibrich J (1999) A Gift of Stories: Discovering How To Deal with Mental IIIness. Otago University Press.

Lindemann Nelson H (2001) Damaged Identities, Narrative Repair. Cornell University Press.

Maruna S (2001) Making Good: How Exconvicts Reform and Rebuild their Lives. American Psychological Association Books.

McAdams DP (2006) The Redemptive Self: Stories Americans Live By. Oxford University Press.

Mezey G, Eastman N (2009) Choice and social inclusion in forensic psychiatry. Acknowledging mixed messages and double think. Journal of Forensic Psychiatry and Psychology 20: 503-7.

NHS London (2006) Report of the Independent Inquiry into the Care and Treatment of John Barrett. NHS London.

Parker T (1994) Life after Life: Interviews with Twelve Murderers. Harper Collins.

Ridgeway PA, Press A (2004) Assessing the Recovery Commitment of Your Mental Health Service: A User's Guide to the Development of Recovery Enhancing Environments Measure (DREEM). National Institute of Mental Health in England.

Roberts G, Holmes J (1998) Healing Stories. Narrative in Psychiatry and Psychotherapy. Oxford University Press.

Roberts G (2000) Narrative and severe mental illness: what place do stories have in an evidence-based world? Advances in Psychiatric Treatment 6: 432-41.

Roberts G, Dorkins E, Wooldridge J, et al (2008) Detained - what's my choice? Part 1: Discussion. Advances in Psychiatric Treatment 14: 172-80.

Royal College of Psychiatrists, Care Services Improvement Partnership \& Social Care Institute for Excellence (2007) A Common Purpose. Recovery in Future Mental Health Services. RCPsych.

Royal College of Psychiatrists (2008) Fair Deal for Mental Health. RCPsych (http://www.rcpsych.ac.uk/campaigns/fairdeal.aspx).

Sadler JZ (2008) Vice and the Diagnostic Classification of Mental Disorders. A Philosophical Case Conference. Philosophy, Psychiatry and Psychology 15: 1-17.

Sainsbury Centre for Mental Health (2010) Implementing Recovery. A Methodology for Organisational Change. SCMH.

Scotland Baroness, Kelly H, Devaux M (1998) The Report of the Luke Warm Luke Mental Health Inquiry Volumes I and II. Lambeth. Southwark and Lewisham Health Authority.

Shepherd G, Boardman J, Slade M (2008) Making Recovery a Reality. Sainsbury Centre for Mental Health.

Slade M (2009) Personal Recovery and Mental IIIness. Cambridge University Press.

Solomon A (2002) The Noonday Demon: An Atlas of Depression. Simon \& Schuster.

Soothill K, Parker T (1999) Criminal Conversations: An Anthology of the Work of Tony Parker. Routledge.

Spence DP (1982) Narrative Truth and Historical Truth: Meaning and Interpretation in Psychoanalysis. WW Norton.

Styron W (1992) Darkness Visible: A Memoir of Madness. Vintage.

Sutton A (1997) Authority, autonomy, responsibility and authorisation: with specific reference to adolescent mental health practice. Journal of Medical Ethics 23: 26-31.

Toombs SK (1993) The Meaning of IIIness. A Phenomenological Account of the Different Perspectives of Physician and Patient. Kluwer Academic Publishers.

Vaillant G (1995) Adaptation to Life. Harvard University Press

Ward T, Gannon TA (2006) Rehabilitation, etiology, and self-regulation. The comprehensive good lives model of treatment for sexual offenders. Aggression and Violent Behavior 11: 77-94.

Ward T, Mann R, Gannon T (2007) The good lives model of offender rehabilitation. Clinical implications. Aggression and Violent Behaviour 12: 87-107. 
MCQs

Select the single best option for each question stem

1 Recovery:

a is an initiative arising from the service user movement

$\mathrm{b}$ is a new concept

c privileges the professional over the patient

d applies only to people with mental illness

e has been well-described in forensic services.

2 In forensic services, recovery:

a is impossible

b has to be applied in the same way as in other services c poses challenges to risk management

$\mathrm{d}$ must take second place to medication

$\mathrm{e}$ is a nursing issue.

3 Illness narratives:

a can enrich patients' views of illness experience

$\mathrm{b}$ are more reliable than professionals' views

c apply only to physical conditions

$\mathrm{d}$ are always critical of professionals' views

e hinder the therapeutic alliance.

4 Autonomy in forensic mental healthcare:

a should be discouraged

$\mathrm{b}$ is easy to assess c is legally enforceable

$\mathrm{d}$ is independent of therapeutic relationships

e can develop over time.

5 Narrative approaches to forensic treatment:

a are applicable only in groups

b enhance perspective-taking by patients

c involve patients writing an account of their life

$\mathrm{d}$ have a strong evidence base

e focus on the patient's past traumas.

\title{
Excerpt from Memoirs of my Nervous IIIness, by Daniel Paul Schreber
}

\author{
Selected by Femi Oyebode
}

I have dealt in detail with my hallucinations in Appendix IV of my Memoirs, and I refer to it at this juncture. From the medical specialist's report I notice with some satisfaction that he himself attributes a certain reality to my hallucinations, in so far as he apparently does not doubt that the "voices" described in my Memoirs are in fact perceived by me. The only difference of opinion then is whether the subjective sensation of hearing voices is cause only by pathological functioning of my own nerves, or whether some external cause acts on them, in other words whether the sound of voices is, so to speak, a trick on the part of my own nerves, or whether some being outside my body speaks into me in the form of voices. Equally the question may be raised concerning "grimacing", the pulling of faces, closing of my eyes, etc., whether it is only a pathological state of my nerves causing muscular contractions or whether there is some external stimulus acting on my body. In essence it is one assertion versus another. Mere rationalism will naturally deny from the start that divine miracles are the cause. But happily rationalism, in Goethe's words, "What cannot be accounted for, does not count", is almost nowhere in science the guiding principle. I who cannot prove the miracles but only wish to put other people in a frame of mind to believe in the possibility of supernatural influences in connection with my person, I would be satisfied if the medical specialist were to affirm that in my case these phenomena have a characteristic and distinct stamp hitherto unknown in scientific experience. I presume that hallucinations of the kind described have never previously been observed except in my case, particularly the incessant talking of voices which cannot be silenced by any mental distraction, is something totally unheard of, as are the muscular contractions against the patient's will (as even the medical expert admits) which force him to shut his eyes, to utter bellowing noises, markedly accelerate his breathing even while at rest, etc. I would also like to see this assumption confirmed in a definite medical statement, unless it can be shown to be incorrect. It would be of particular value to me if the medical expert could also confirm that closing of my eyes - against my will - occurs regularly and immediately as soon as I am silent after taking part in a loud conversation, in other words when I indulge in thinking nothing.
IN OTHER WORDS
Daniel Schreber (1842-1911) was a President of a Panel of Judges at the Court of Appeal at Dresden. Schreber's first episode of mental illness was in the autumn of 1884 He was admitted to the Psychiatric Clinic of the University of Leipzig in December 1884 and had fully recovered by June 1885 . The second episode of illness started in October 1893. He was admitted to hospital again in that year and remained there until 1903. His final admission was in 1907, and he remained in hospital until his death in 1911. Schreber's account of his mental illness has attracted the interest of many psychiatrists, including Freud, Jaspers and others. This excerpt is from Memoirs of My Nervous IIIness (translated and edited by Ida MacAlpine \& Richard A Hunter) Wm Dawson \& Sons Ltd, 1955. doi: 10.1192/apt.17.3.187 